\title{
Internacionalização e multidisciplinaridade - um novo rumo para os nossos suplementos
}

\author{
Internationalization and multidisciplinarity - \\ a new perspective for our supplements
}

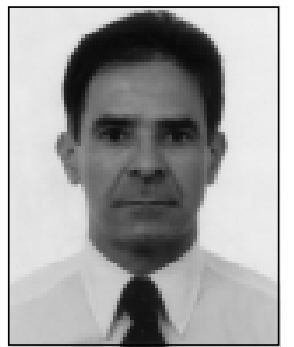

Paulo Augusto Moreira Camargos ${ }^{1}$

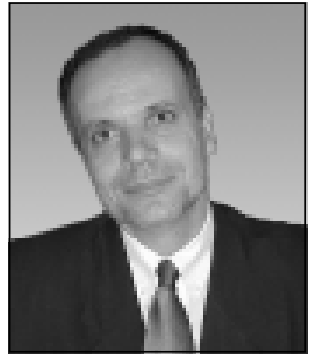

Sérgio Luís Amantéa 2

Os suplementos do Jornal de Pediatria têm sido elaborados com a participação de profissionais com reconhecida atuação nas respectivas subespecialidades em nosso país. Nos últimos quatro anos, têm procurado acompanhar a evolução científica da revista e cumprido o objetivo de trazer artigos de revisão atualizados, com tópicos de interesse para todos aqueles que atuam na assistência direcionada para a população infantil.

Dentro deste contexto, num momento em que os avanços da ciência e a velocidade da informação rompem as barreiras de tempo e espaço, ao estruturarmos o enfoque central deste suplemento, não deixamos de considerar tal paradigma.

Primeiro procuramos estabelecer um enfoque multidisciplinar para a doença respiratória infantil. Um domínio não centrado na pneumologia de maneira exclusiva, mas agregando a participação de neonatologistas, intensivistas, infectologistas, gastrenterologistas, imunologistas, cirurgiões (pediátricos, torácicos) e fisioterapeutas. Uma interdisciplinaridade direcionada para os transtornos pulmonares. Uma abordagem global, com tópicos selecionados por critérios epidemiológicos e pelo impacto das informações na prática clínica cotidiana.

1. Professor Adjunto, Doutor, Mestre em Medicina, Departamento de Pediatria, Disciplina de Pneumologia Pediátrica da Faculdade de Medicina da Universidade Federal de Minas Gerais (UFMG).

2. Professor Adjunto, Depto. de Pediatria e Puericultura - Fundação Faculdade Federal de Ciências Médicas de Porto Alegre (FFCMPA). Doutor em Pneumologia. Chefe do Serviço de Emergência - Hospital da Criança Santo Antônio, Irmandade Santa Casa de Misericórdia de Porto Alegre. 
Da mesma maneira, resolvemos romper nossas fronteiras geográficas. Para isto, os artigos contaram com a participação de vários colaboradores de outros países. Uma globalização da informação, uma discussão em tempo real, um confronto de opiniões. A continuidade de um processo de "internacionalização" do Jornal de Pediatria que contribui, ainda mais, para a sua destacada inserção na vanguarda científica da pediatria da América Latina.

A compilação de artigos de revisão acerca de um tema costuma possibilitar um contato abrangente com a pesquisa e o conhecimento consolidado, o que facilita a aquisição de um juízo fundamentado, mesmo para questões ainda emergentes ou polêmicas.

Esperamos que este número seja capaz de cumprir os seus objetivos, e possa proporcionar ao leitor uma revisão atualizada de tópicos especialmente selecionados, que atendam às expectativas daqueles que estão envolvidos com a assistência pediátrica, sejam eles internistas ou pneumopediatras, mas particularmente com interesse direcionado para a área da terapia respiratória.

Gostaríamos de aproveitar a oportunidade para também agradecer a todos os nossos colaboradores, nacionais e estrangeiros, que se associaram ao projeto e não pouparam esforços para transformá-lo em realidade. 